\title{
Glucose metabolism in subjects of Mapuche ethnicity and descendants of Europeans: A systematic review and meta-analysis
}

\author{
J.C. Fernández-Cao and C. Doepking \\ Departamento de Nutrición y Dietética, Facultad de Ciencias de la Salud, Universidad de Atacama, Avenida \\ Copayapu 2862, Copiapó, Chile.
}

The aim of this study was to compare the insulin resistance and the glucose and insulin concentration between subjects of Mapuche ethnicity and descendants of Europeans.

Study registered in Prospero (CRD42017069924). The search was carried out in Pubmed/Medline, Scopus, Web of Science and Scielo until June 16, 2017. Observational studies conducted on adult subjects, of both sexes, of Mapuche ethnicity and descendants of Europeans residents in Chile, who presented data on the mean and standard deviation of insulin resistance, glucose and insulin were included. The first selection of studies was carried out from the title and the abstract. All potential relevant manuscripts were examined in full to determine if they finally met the selection criteria. Data were expressed as mean differences, and they were calculated as the difference between the values of glucose, insulin and insulin resistance in subjects of Mapuche ethnicity and descendants of Europeans. The global mean difference (GMD) and the $95 \%$ confidence interval (CI) were calculated using the generic inverse variance method with random effects models. Stratified analyses were carried out to examine the influence of the area of residence, rural or urban. The Cochran test and the $\mathrm{I}^{2}$ statistic were used to study the heterogeneity between the studies. The publication bias was evaluated using the Begg tests. All analyzes were performed using STATA 15.0.

2314 manuscripts were identified, of which four were selected (1-4). Through stratified analysis, significant differences between subjects of Mapuche ethnicity and descendants of Europeans, were found in insulin levels and insulin resistance in rural areas, 3.28pmol/L (95\% CI: 1.69, 4.87) and 0.81 (95\% CI: 0.43, 1.19), respectively. These differences were even more evident in urban areas, $14.97 \rho m o l / L$ (95\% CI: 12.20, 17.74), for insulin and 3.41 (95\% CI: 2.52, 4.30) for insulin resistance (Figure 1). Heterogeneity was low or undetectable in all sub-analyses, and no evidence of publication bias was found in any meta-analyses.

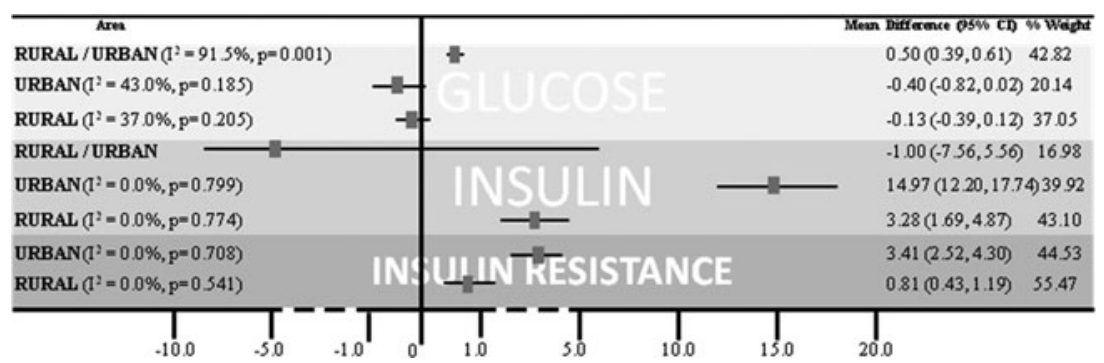

Fig. 1. Forest plot of GMD for glucose, insulin and insulin resistance in subjects of Mapuche ethnicity and descendents of Europeans, stratified by the area of residence (rural/urban, urban or reral).

Findings suggest a higher insulin levels and insulin resistance in subjects of Mapuche ethnicity than in descendants of Europeans. Differences seem to be more outstanding in urban areas, suggesting that changes in diet and lifestyle caused by the transition from rural to urban areas, may have an especial harmful effect on subjects of Mapuche ethnicity.

1. Miquel JF, Covarrubias C, Villaroel L, Mingrone G, Greco AV, Puglielli L et al. (1998) Genetic epidemiology of cholesterol cholelithiasis among Chilean Hispanics, Amerindians, and Maoris. Gastroenterology 115(4), 937-46.

2. Gälman C, Miquel JF, Pérez RM, Einarsson C, Ståhle L, Marshall G et al. (2004) Bile acid synthesis is increased in chilean hispanics with gallstones and in gallstone high-risk Mapuche Indians. Gastroenterology 126(3), 741-8.

3. Celis-Morales CA, Perez-Bravo F, Ibañes L, Sanzana R, Hormazabal E, Ulloa N et al. (2011) Insulin resistance in chileans of European and indigenous descent: Evidence for an ethnicity x environment interaction. PLoS One 6(9).

4. Navarrete BC, Cartes-Velásquez R (2012) Prevalencia de diabetes tipo 2 y obesidad en comunidades Pehuenches, Alto Biobio. Rev Chil Nutr 39(3), $7-10$. 